\title{
Uma nova espécie de Fannia Robineau-Desvoidy, 1830 do Brasil (Diptera, Fanniidae)
}

\author{
Márcia Souto Couri 1,2 \\ Paulo Francisco de Araújo 1,3
}

\begin{abstract}
Fannia pamplonae sp.n. from Rio de Janeiro, Brazil, is describe (Diptera, Fanniidae).
\end{abstract}

Fannia pamplonae sp. $\mathbf{n}$

(Figs. 1 - 8)

Coloração geral: Castanho-escura com leve brilho metálico: vita frontal negra. Antena negra com polinosidade prateada no terceiro artículo, arista castanhoescura. Lúnula negra. Parafaciália com polinosidade prateada, vista sob certa luminosidade. Palpo negro. Tórax no terço apical do escuto e do escutelo com leve polinosidade prateada. Balacim amarelo. Caliptras amarelas, com os bordos levemente castanhos. Asa acastanhada, mais intensamente nos machos. Abdômen trimaculado. Comprimento total: $3,9-4,1 \mathrm{~mm}$.

Macho. Cabeça:Olhos ciliados, ocupando quase toda a cabeça. Espaço interocular, no nível do ocelo anterior, cerca de 0,19 da largura da cabeça. Cerdas frontais em número de 12 pares iniciados na lúnula e terminados logo abaixo do ocelo anterior. Arista levemente pubescente. Antena inserida logo abaixo do nível na metade dos olhos, longa e com o terceiro artículo medindo cerca de 2,6 vezes o comprimento do segundo, gena estreita. Vibrissa forte, inserida acima da margem oral. Palpo filiforme.

Torax: Cerdas acrosticais 0:1; dorso-centrais 2:3; pré-alar presente, cerca de um terço do comprimento da notopleural posterior; intra-alares 1:2; supra-alar 1; pós-alar 2; pós-pronotais 3. Noto-pleura com 2 cerdas desenvolvidas, de comprimento semelhante entre si; anepímero com uma fileira de 5 cerdas longas, a superior mais desenvolvida. Cerdas catepisternais 1:1. Escutelo com um par de cerdas basais laterais longas, um par pré-apical discal curto e um par apical longo cerca de 1,5 vezes o comprimento do par basal lateral. Perna anterior: Coxa, na face póstero-ventral com duas cerdas apicais longas; femur, na face dorsal com uma fileira de 4

1. Museu Nacional, UFRJ, 20942, Rio de Janeiro, Brasil.

2. Bolsista do CNPq

3. Bolsista do CEPG 
cerdas inseridas no terço apical; face ventral com uma fileira completa de cerdas longas no terço apical; tíbia, na face dorsal, com uma cerda longa pré-apical; face ventral com uma cerda apical; pré-tarso mediando de 0,46 da soma dos demais segmentos tarsais. Perna mediana: Fêmur, na face póstero-ventral com uma fileira de cerdas espaçadas, na face ventral com uma fileira completa de cerdas, mais desenvolvidas no terço apical; tibia alargando-se em direção ao ápice, face ventral com uma cerda apical longa. Perna posterior (figura 1): Coxa na face posterior com cílios curtos; fêmur, na face dorsal com uma cerda pré-apical, face postero-dorsal com 3 cerdas longas inseridas no terço apical, face anterior com uma fileira de cerdas nos dois terços basais, face ventral com uma fileira de 7-8 cerdas no terço médio e uma cerda pré-apical, face póstero-ventral com cerdas longas inseridas no terço médio não formando tufo; tíbia, na face dorsal com uma cerda sub-mediana e uma préapical, face ântero-dorsal com uma fileira de cerdas, face ântero-ventral com uma cerda sub-mediana e uma apical, face póstero-ventral com uma cerda apical.

Abdômen: Quinto esternito com membrana anterior quase reta e com cerdas fortes (fig. 2).

Genitália: Placa cercal de forma oval, surstili com uma projeção lateral externa, na qual se inserem duas cerdas (fig. 3). Apódema do aedeagus longo, ultrapassando a margem do hipândrio e com ápice alargado (fig. 4 e 5).

Fêmea: (fig. 6-8). Material muito danificado, permitindo registrar apenas as seguintes diferenças em relação ao macho:

Cabeça: Espaço interocular, no nível do ocelo anterior, cerca de 0,35 da largura da cabeça.

Tórax: Fêmur posterior, na face póstero-ventral, sem cerdas longas.

Genitália: Ovipositor largo; com microtríquias nos tergitos e esternitos; esternito VIII com duas placas medianas esclerotinizadas com duas cerdas fortes, a superior cerca do dobro do comprimento da anterior (fig. 6-7). Espermatecas piriformes, em número de duas (fig. 8).

Holotipo macho. Brasil, Rio de Janeiro, Realengo, 30.VII.1988, M.S. Couri, D. Pamplona, P.F. Araújo e J.R. Pujol-Luz col. Parátipos: 2 machos e 2 fêmeas, com os mesmos dados do holotipo. Os exemplares foram coletados voando sobre as fezes frescas de cavalo, na sombra.

Discussão: esta espécie pertence ao grupo canicularis, e ao sub-grupo pusio (ALBUQUERQUE et al., 1981). Na chave de ALBUQUERQUE et al. (op. cit.), $F$. pamplonae sp.n. aproxima-se de $F$. trimaculara (STEIN, 1898), podendo ser segregada pela seguinte chave:

- Fêmur posterior, na face ântero-ventral, com 7-8 cerdas longas e retas inseridas no terço médio; face póstero-ventral sem cerdas longas no terço mé-

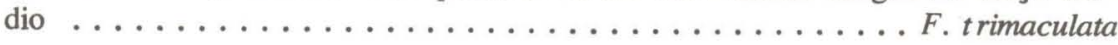

- Fêmur posterior, ântero-ventral, sem tais cerdas; face póstero-ventral com cerdas longas inseridas no terço médio ............ pamplonae $\mathbf{s p .} \mathbf{n}$.

O nome desta espécie foi dado em homenagem à professora Denise Pamplona, nossa companheira no estudo dos Diptera. 

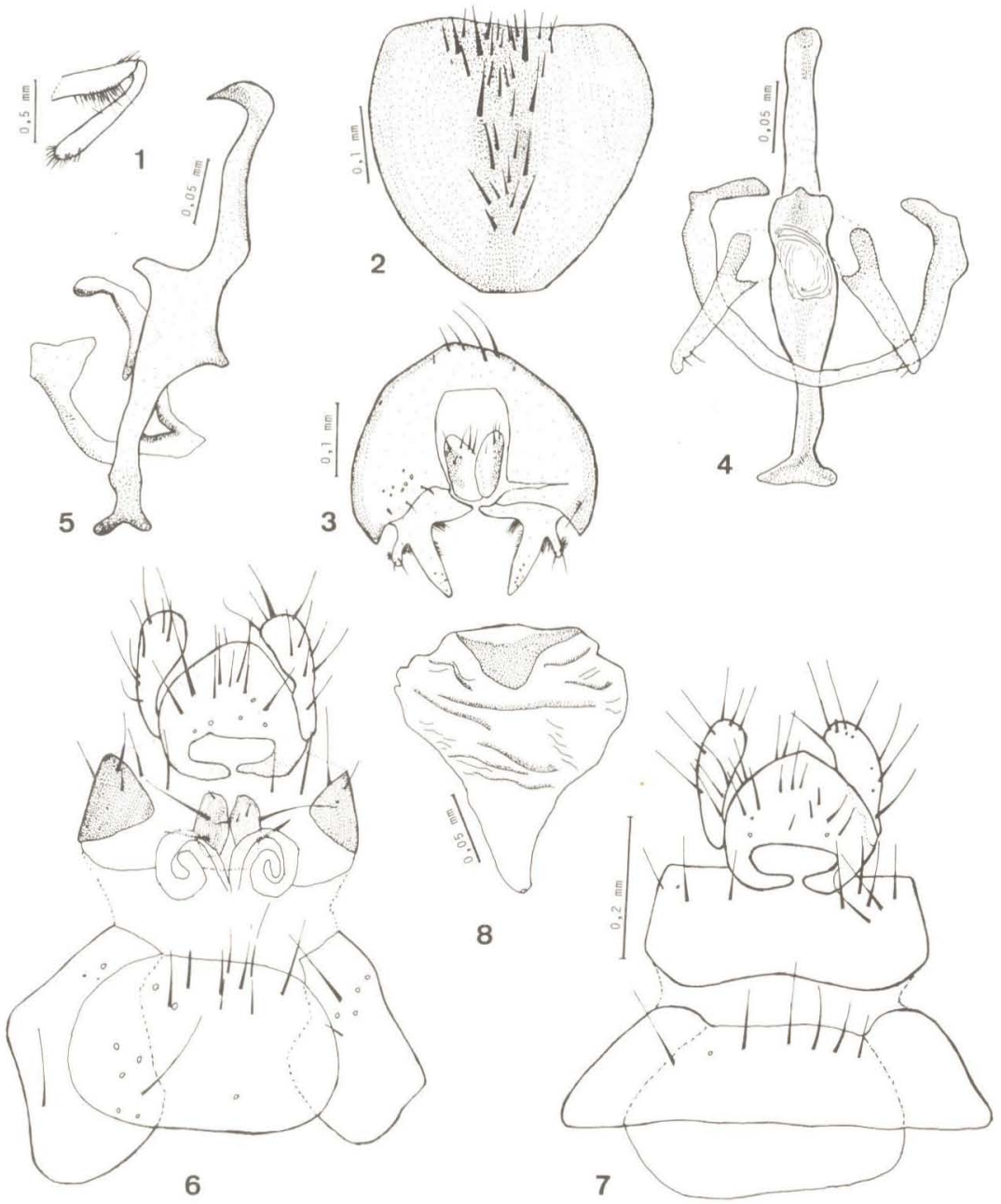

Fig. 1-8. Fannia pamplonae sp. n. 1, Perna posterior do macho, vista posterior; 2, Quinto esternito do macho; 3, Placa cercal e sursitili, vista dorsal; 4, Complexo fálico, vista dorsal; 5, Complexo fálico, vista lateral; 6, Ovipositor, vista ventral; 7, Ovipositor, vista dorsal; 8, Espermateca. 
Revta bras. Zool.

\section{REFERENCIA}

ALBUQUERQUE, D. DE O., D. PAMPLONA. C.J.B. DE CARVALHO. 1981 Contribuição ao conhecimento de Fannia R.D. 1830 da região Neotropical (Diptera, Fanniidae). Arq. Mus. Nac. RJ, 56: 9-34, 60 figs. 